\title{
Qualidade físico-química de mortadelas e carnes moídas e conhecimento dos consumidores na conservação destes produtos
}

\author{
Quality physicist-chemistry of mortadelas and pounded meats and \\ knowledge of the consumer in the conservation of these
}

\section{Fernanda Vilares Escaleira da CONCEIÇÃO ${ }^{1}$, Édira Castello Branco de Andrade GONÇALVES ${ }^{1 \star}$}

\begin{abstract}
Resumo
Produtos cárneos apresentam uma composição que facilita sua deterioração, e cuidados desde a produção ao consumo garantem sua qualidade. Avaliaram-se pH, temperatura, cálcio, umidade, gás sulfídrico e sulfito de carnes moídas e mortadelas, e o conhecimento do consumidor na conservação destes produtos. Quanto ao $\mathrm{pH}$, todas as amostras de carnes moídas e duas de mortadelas estavam fora do padrão estabelecido por LANARA. A temperatura de $60 \%$ das amostras estava superior ao preconizado. Todas as amostras estavam dentro dos padrões quanto ao teor de cálcio e umidade. Todas as carnes moídas e $92 \%$ das mortadelas apresentaram gás sulfídrico. A presença de sulfito foi observada em $47 \%$ das carnes moídas. Analisando-se os rótulos observou-se que $20 \%$ das mortadelas não condiziam quanto ao teor de cálcio e $57 \%$ das mortadelas e $40 \%$ das carnes moídas não condiziam com o valor estabelecido para a umidade. Apenas $60 \%$ dos consumidores observam a temperatura de conservação dos produtos cárneos nos postos de vendas, mas isto é feito utilizando o "tato", o que obviamente não condiz com o valor real da temperatura, e é comum o congelamento destes na própria embalagem. Acredita-se que a indústria e o estabelecimento comercializador devam ser fiscalizados com maior rigor e que ações educativas do consumidor devam ser estimuladas visando a garantia da qualidade no setor de alimentos.
\end{abstract}

Palavras-chave: mortadela; carne moída; qualidade físico-química.

\begin{abstract}
Meat products present a composition that facilitates its deterioration. Cares since the production to the consumption guarantee its quality. Was evaluated $\mathrm{pH}$, temperature, calcium, humidity, sulfídrico gas and sulfite of pounded meats and mortadelas, and the knowledge of the consumer in the conservation of these. Respecting to $\mathrm{pH}$, all the samples of pounded meats and 2 of mortadelas were of the established one for LANARA. The temperature of $60 \%$ of the samples was superior to the praised one. All the samples were inside of the standards respecting to the composition of calcium and humidity. All pounded meats and $92 \%$ of mortadelas had presented sulfídric gas. The sulfite presence was observed in $47 \%$ of the pounded meats. Analyzing the label it was observed that $20 \%$ of mortadelas did not respecting to the calcium composition and $57 \%$ of mortadelas and $40 \%$ of the pounded meats did not for humidity. But $60 \%$ of the consumers observe the temperature of conservation of the meat products in the ranks of selling ("contact") and the freezing of these in the proper packing is common. One gives credit that the industry and the comercializador establishment must be fiscalized with bigger severity and that educative actions of the consumer must be stimulated aiming at the guarantee of the quality in the food sector.

Keywords: mortadela; pounded meat; quality physicist-chemistry.
\end{abstract}

\section{Introdução}

Produto cárneo é toda carne na qual as propriedades da carne fresca tenham sido alteradas por um ou mais dos seguintes procedimentos: moagem, floculação ou emulsão, adição de temperos, adição de agentes da cura ou tratamento térmico. Um produto cárneo bastante utilizado devido à versatilidade em preparações culinárias é a carne moída. De acordo com o Regulamento Técnico de Identidade e Qualidade de Carne Moída este é um produto cárneo obtido a partir da moagem de massas musculares de carcaças de bovinos, seguida de imediato resfriamento ou congelamento. A matéria-prima a ser utilizada deverá estar isenta de tecidos inferiores como ossos, cartilagens, gordura parcial, aponevroses, tendões, coágulos, nodos linfáticos, etc. (BRASIL, 2003).
Não é permitida a obtenção do produto a partir de moagem de carnes oriundas da raspa de ossos e carne mecanicamente separada - CMS, e a carne moída resfriada deve ser mantida à temperatura de $0 \mathrm{a} 4{ }^{\circ} \mathrm{C}$. Como preconizado por Métodos Analíticos para Controle de Produtos de Origem Animal - LANARA e seus ingredientes, a carne própria para consumo deve ter $\mathrm{pH}$ entre 5,8 e 6,2. O pH 6,4 indica carne para consumo imediato e, acima disso, início de decomposição (BRASIL, 1989). A carne moída é um produto que adquire características sensoriais insatisfatórias rapidamente e para diminuir as perdas com sua deterioração, o comércio utiliza um artifício fraudulento que é a adição de um conservante intencional, o sulfito de sódio, colocando em risco a saúde do consumidor. O uso de sulfitos em

Recebido para publicação em 16/8/2007

Aceito para publicação em 8/7/2008 (002777)

Departamento de Tecnologia dos Alimentos, Escola de Nutrição, Universidade Federal do Estado do Rio de Janeiro - UNIRIO, Av. Pasteur, 296, Urca, CEP 22290-240,

E-mail:ediracba@analisedealimentos.com.br

${ }^{*}$ A quem a correspondência deve ser enviada 
carnes e derivados intensifica a cor, restaura sua cor primitiva e elimina odores desagradáveis, dando a aparência de produto fresco (PIROLA, 2006).

Entende-se por decomposição da carne a divisão da matériaorgânica, principalmente de natureza proteica, pela ação de bactérias que decompõem a carne em várias substâncias químicas, muitas das quais são gasosas e com cheiro fétido, dentre elas gases como o hidrogênio sulfurado, o dióxido de carbono, a metana e a amônia (THORTON, 1968).

Outro produto cárneo de alto consumo, por ser de fácil poder aquisitivo, é a mortadela. De acordo com o Regulamento Técnico de Identidade e Qualidade de Mortadela este é um produto cárneo industrializado obtido de uma emulsão das carnes de uma ou mais espécies de animais de açougue, adicionado ou não de toucinho, ingredientes, embutido em envoltório natural ou artificial de diferentes formas, submetido ao tratamento térmico adequado, defumado ou não (BRASIL, 2000).

O limite máximo estabelecido para quantidade de CMS é de $60 \%$ para mortadelas (sem denominação), $40 \%$ para mortadelas de ave e $20 \%$ para mortadelas tipo Bologna. O valor estabelecido para teor de cálcio em base seca para mortadelas é de $0,9 \%$, para mortadelas tipo Bologna é de $0,3 \%$ e para mortadelas de ave é de 0,6\% (BRASIL, 2000). O teor de cálcio nas mortadelas possui estreita relação com a quantidade de CMS adicionada em sua composição. Em relação à temperatura de armazenamento, a Vigilância Sanitária prevê uma faixa de 3 a $8^{\circ} \mathrm{C}$ (BRASIL, 1999).

A umidade é um requisito extremamente importante na classificação da mortadela, pois está diretamente relacionada com suas condições higiênico-sanitárias, já que acima do recomendado pode proporcionar a proliferação de microrganismos patogênicos (FRANCO, 2003). De acordo com o Ministério da Agricultura o teor máximo é de 65\% (BRASIL, 2000). Como preconizado por LANARA, o pH de mortadelas deve ser na faixa da neutralidade, 7,0 (BRASIL, 1989).

De acordo com a Resolução de Diretoria Colegiada - RDC $n^{\circ} 360$ de 23 de dezembro de 2003, Rotulagem Nutricional é toda descrição destinada a informar ao consumidor sobre as propriedades nutricionais de um alimento. Quanto à composição nutricional dos produtos, é admitida uma tolerância de no máximo $20 \%$ em relação aos valores de nutrientes declarados no rótulo (BRASIL, 2003).

Alguns aspectos essenciais devem ser observados no momento da compra de produtos cárneos. Estes aspectos relacionam-se ao produto e ao estabelecimento comercial e, em conjunto, garantem a qualidade do produto a ser adquirido. É importante observar a higiene do estabelecimento comercial, balcões frigoríficos e funcionários, as condições de temperatura em que estes produtos são mantidos e suas características sensoriais, além de informações cruciais apresentadas no rótulo do produto, como prazo de validade, temperatura de conservação, dentre outras.

Assim, o objetivo deste estudo foi avaliar a qualidade físicoquímica de mortadelas e carnes moídas em diferentes pontos de venda nas cidades do Rio de Janeiro e Niterói, bem como o conhecimento do consumidor quanto à conservação destes produtos.

\section{Material e métodos}

\subsection{Amostras}

Amostras de mortadela $(\mathrm{N}=8)$, mortadela do tipo Bologna $(\mathrm{N}=4)$, mortadela de ave $(\mathrm{N}=4)$ e mortadelas vendidas a granel $(\mathrm{N}=4)$ de diferentes marcas, em dois lotes, foram analisadas quanto às suas características físico-químicas. Amostras de carne moída bovina $(\mathrm{N}=20)$ em dois lotes, comercializadas por diferentes redes de supermercados nas cidades do Rio de Janeiro e Niterói, também foram analisadas. Os lotes, quando não presentes nos rótulos dos produtos, foram considerados por diferentes datas de aquisição com intervalo superior a 7 dias.

\subsection{Análises físico-químicas}

Medida da temperatura: Foi feita a medida da temperatura nas amostras nos postos de venda e no laboratório de análise de alimentos da Escola de Nutrição-UNIRIO, simulando o "local de consumo". O termômetro foi introduzido no interior do produto e a leitura registrada. Foram feitas leituras em 3 pontos distintos, considerando-se o meio e os extremos direito e esquerdo.

Medida de $\mathrm{pH}$ : Foi feita a medida do $\mathrm{pH}$ em dois pontos distintos das amostras, utilizando-se fita de $\mathrm{pH}$, no ponto de venda e no "local de consumo".

Teste de sulfito: $\mathrm{O}$ teste de sulfito foi realizado nas amostras de carne moída utilizando-se indicador Verde de Malaquita (ANDRADE, 2006). O teste foi realizado em duplicata.

Teste de gás sulfídrico: O teste de gás sulfídrico foi feito utilizando-se Pumblito de sódio (ANDRADE, 2006). Este teste foi feito em duplicata.

Umidade: A determinação da umidade foi feita por dessecação em estufa a $105^{\circ} \mathrm{C}$ (ANDRADE, 2006). Esta análise foi feita em quadriplicata.

Determinação do teor de cálcio: As amostras passaram por processo de calcinação e foi feita a determinação do teor de cálcio através da volumetria utilizando-se o EDTA (BRASIL, 2005). A análise foi feita em quadriplicata.

\subsection{Tratamento estatístico}

Na rejeição dos dados físico-químicos foi aplicado o teste de Dixon, e o teste $T$ de Student foi utilizado na avaliação do produto em relação à legislação e às informações fornecidas pela rotulagem nutricional.

\subsection{Rotulagem}

Os ingredientes utilizados na fabricação das amostras de mortadela foram analisados de acordo com o Regulamento Técnico de Identidade e Qualidade de Mortadela - Instrução Normativa $\mathrm{n}^{\circ} 4$ de 31 de março de 2000 do Ministério da Agricultura.

A rotulagem das amostras de mortadela foi comparada com os resultados obtidos na análise do teor de cálcio acordo com a RDC n 360 .

Os teores encontrados para umidade em mortadelas e carnes moídas foram comparados com as rotulagens, considerando-se 
valores calculados a partir da composição dos nutrientes, e avaliados de acordo com a RDC $\mathrm{n}^{\circ} 360$ e com o preconizado máximo $65 \%$.

\subsection{Cuidados na compra e conservação de produtos cárneos}

Foi aplicado um questionário a 100 indivíduos frequentadores de supermercados abrangendo questões quanto à rotulagem, frequência de compra, condições de transporte e armazenamento de produtos cárneos, visando avaliar o conhecimento do consumidor a respeito dos cuidados que se deve ter ao comprar e ao armazenar estes produtos. O questionário aplicado encontrase na Figura 1.

\section{Resultados e discussão}

\subsection{Análises físico-químicas}

Os resultados encontrados na medida das temperaturas de amostras de carnes moídas e mortadelas nos postos de venda encontram-se nas Figuras 2 e 3, respectivamente.

Como representado nas Figuras 2 e 3 , percebe-se que a maior parte da amostras estava sendo armazenada a temperaturas inadequadas, oferecendo riscos à qualidade higiênico-sanitária do produto e, consequentemente, à saúde do consumidor.

Um estudo realizado por Góes et al. (2004) avaliou a adequação da temperatura de conservação de alimentos refrigerados quanto às recomendações do fabricante em carnes e derivados e diagnosticou que $30 \%$ das amostras avaliadas estavam fora dos padrões (GÓES et al., 2004), resultado menos preocupante que o encontrado no presente trabalho.

Em relação ao $\mathrm{pH}$, tanto para mortadelas quanto para carnes moídas não houve diferença entre os valores encontrados no ponto de venda e na chegada ao laboratório. Todas as amostras de mortadela apresentaram pH 7,0, com exceção das amostras das marcas D e F, com valores de 8,0 e 6,0, respectivamente. Todas as amostras de carne moída apresentaram pH entre 6,5 e 7. De acordo com as normas do LANARA, carnes moídas com pH acima de 6,4 estão em início de decomposição (BRASIL, 1989).

Os resultados obtidos no teste de sulfito estão representados na Figura 4.

Pode-se perceber que $48 \%$ das amostras revelaram adição de sulfito. O sulfito tem a propriedade de devolver, às carnes em deterioração, odor e cor próprios de carnes frescas, mascarando as reais condições do produto. Em um estudo realizado por Pirola (2006) no município de Niterói, Rio de Janeiro, com 30 amostras de carne moída, 17 apresentaram resultado positivo para este teste (PIROLA, 2006). Ambos os resultados mostram que esta prática é comum e que nem sempre o consumidor está adquirindo carnes tão frescas quanto imagina.

Quanto ao teste de gás sulfídrico, apenas duas amostras de mortadela apresentaram resultado negativo. Todas as amostras de carne moída apresentaram resultado positivo para o mesmo teste. Assim, nota-se haver inadequações na manipulação e/ou na cadeia de frio que justifiquem a presença deste gás em quase $97 \%$ das amostras analisadas, já que ele indica decomposição do produto.
A determinação do teor de umidade revelou que todas as amostras de mortadela estavam de acordo com a legislação, máximo de 65\% (BRASIL, 2000).

Os resultados encontrados na comparação entre teores de umidade encontrados para carnes moídas e mortadelas com as respectivas rotulagens estão dispostos nas Figuras 5 e 6 .

Como observado na Figura 5, 40\% das amostras de carne moída apresentaram inconformidade entre valores encontrados para umidade. Este valor foi calculado a partir da composição dos nutrientes declarados na rotulagem. Conforme a RDC $n^{\circ} 360$, o limite para aceitação é, no máximo, 20\% do valor. As demais amostras apresentaram valores entre 2 e 19,60\% acima do declarado.

Na Figura 6 nota-se que 57\% das amostras de mortadela não estavam em conformidade com a RDC n ${ }^{\circ} 360$. As demais amostras apresentaram valores de umidade entre 8,20 e 18,52\% acima do calculado.

Valores de umidade acima do declarado indicam substituição de nutrientes por água. Produtos nestas condições detêm um valor nutricional menor do que o especificado. Carnes com umidades em torno de $82 \%$, como encontradas no estudo, fornecem quantidade significativamente inferior de nutrientes que amostras com umidades de 64\%, também encontradas. A perda tanto de macro quanto de micronutrientes deve ser considerada, já que carnes são a maior fonte de proteína de excelente qualidade, e que carnes moídas especificamente são a principal fonte de proteína e ferro heme de pessoas com menor poder aquisitivo.

A análise do teor de cálcio mostrou que tanto as amostras de carnes moídas quanto as de mortadelas estavam dentro do especificado pela legislação. Duas marcas de mortadelas vendidas a granel foram as que mais se aproximaram do limite estabelecido pela legislação, máximo de $0,9 \%$, com valores de 0,88 e $0,87 \%$. Uma hipótese para o resultado encontrado é que pode se tratar de produtos com qualidade inferior aos demais e possuírem maior teor de CMS em sua constituição.

\section{Rotulagem}

Duas amostras de mortadelas, cujos rótulos apresentavam a denominação de Mortadela Bologna, continham em sua composição CMS, não aceitável pelo Ministério da Agricultura para tal classificação. Cabe lembrar que a mortadela do tipo Bologna permite adição de CMS até o limite máximo de $20 \%$. Estas amostras certamente passaram por um processo de classificação inadequado, devendo apresentar a denominação "tipo Bologna” e não "Bologna”

Os resultados divergentes encontrados na comparação da rotulagem com os teores de cálcio encontrados em amostras de mortadelas estão dispostos na Figura 7.

A amostra A, mortadela sem denominação, apresentou teor de cálcio inferior ao valor descrito na rotulagem do produto. As amostras $\mathrm{N}$ e $\mathrm{P}$, mortadelas de frango, apresentaram valores de mais de $70 \%$ superior ao indicado no rótulo. A CMS de frango vem sendo bastante utilizada em produtos cárneos 


\section{Questionário}

Você está sendo convidado (a) para participar de uma pesquisa que vem sendo desenvolvida pela Escola de Nutrição da UNIRIO visando avaliar a rotulagem nutricional e a qualidade de produtos cárneos.

Aceitando participar deste estudo, pedimos que responda o questionário a seguir e o termo de participação.

Desde de já somos gratos,

$$
\text { Grupo de Pesquisa - Controle de Qualidade de Alimentos }
$$

$$
\text { UNIRIO - EN - DTA }
$$

Termo de participação: Aceito participar da pesquisa

CONTROLE HIGIÊNICO-SANITÁRIO DE PRODUTOS CÁRNEOS

respondendo ao questionário a seguir.

Nome:

Idade:

assinatura

1. Ao comprar um produto cárneo, o que o sr(a) observa no produto?

2. O sr(a) tem por hábito ler o rótulo destes produtos?
( ) $\operatorname{sim}$
( ) não

3. O que costuma observar no rótulo?
( ) data de validade
( ) data de embalagem
( ) origem
( ) informações nutricionais
( ) temperatura de conservação

4. Costuma observar a temperatura do balcão destes produtos?
( ) $\operatorname{sim}$
( ) não

5. Com qual freqüência compra produtos cárneos?
( ) diariamente
( ) semanalmente
( ) quinzenalmente
( ) mensalmente
( ) outros

6. Na seqüência de suas compras os produtos cárneos são colocados no carrinho em que momento?
( ) início
( ) meio
( ) indo para o caixa
( ) não soube informar
( ) outros

7. O transporte dos produtos cárneos até sua residência é feito como?

8. Ao chegar em sua residência esses produtos são guardados:
( ) imediatamente
( ) após limpeza de aparas/corte
( ) sem preocupação

9. Como os produtos cárneos são embalados para o estoque?
( ) mantém embalagem original
( ) corta em pedaços e envolve em filme PVC
( ) Embala integralmente em filme PVC
( ) Guarda em potes plásticos

10. Os produtos cárneos são estocados em:
( ) refrigerador
( ) congelador
( ) freezer

Figura 1. Questionário aplicado a 100 indivíduos frequentadores de supermercados na cidade do Rio de Janeiro em março de 2007. 
(THORTON, 1968). Portanto, era esperado que em mortadelas de ave houvesse esse resultado.

A marca G continha no rótulo a informação "Quantidade não significativa”. O teor de cálcio encontrado para ela foi de $0,83 \mathrm{~g} \%$, ou seja, apenas $0,07 \%$ abaixo do máximo estipulado para mortadelas que é $0,90 \mathrm{~g} \%$. Sendo assim, a quantidade de cálcio presente nessa amostra é significativa.

Quanto às mortadelas tipo Bologna, em nenhuma das marcas analisadas constava a quantidade de cálcio em sua rotulagem. A marca que apresentou menor teor de cálcio, marca K, indicava no rótulo quantidade não significativa deste mineral.

A quantidade de CMS utilizada na elaboração de produtos cárneos é fator determinante em sua qualidade. O processo de separação mecânica altera as propriedades funcionais da carne, modificando as características físico-químicas e sensoriais dos produtos que a contenham, principalmente em relação à textura (FREITAS, 2004).
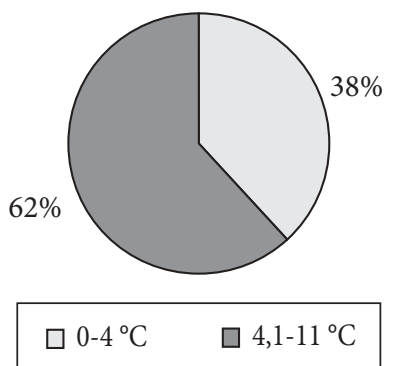

Figura 2. Temperaturas das amostras de mortadelas, mortadelas tipo Bologna, mortadelas de ave e mortadelas vendidas a granel em diferentes pontos de venda na cidade do Rio de Janeiro.

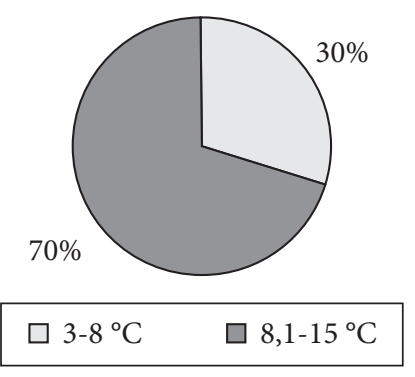

Figura 3. Temperatura $\left({ }^{\circ} \mathrm{C}\right)$ das amostras de carne moída comercializadas em diferentes pontos de venda nas cidades do Rio de Janeiro e Niterói.

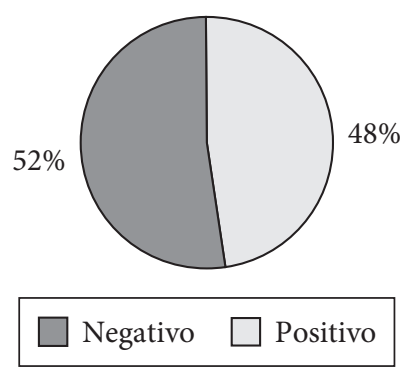

Figura 4. Teste de sulfito em amostras de carnes moídas comercializadas em diferentes pontos de venda nas cidades do Rio de Janeiro e Niterói.

\section{Cuidados na compra e conservação de produtos cárneos}

O questionário utilizado na avaliação do conhecimento do consumidor a respeito dos cuidados que se deve ter ao comprar e ao armazenar produtos cárneos foi aplicado a 100 indivíduos, $71 \%$ mulheres e $29 \%$ homens, faixa etária de 21 a 84 anos.

A Figura 8 apresenta dados que o consumidor observa na aquisição de produtos cárneos.

Dentre os $84 \%$ dos entrevistados que afirmaram se interessar por uma ou mais informações contidas na rotulagem, validade e

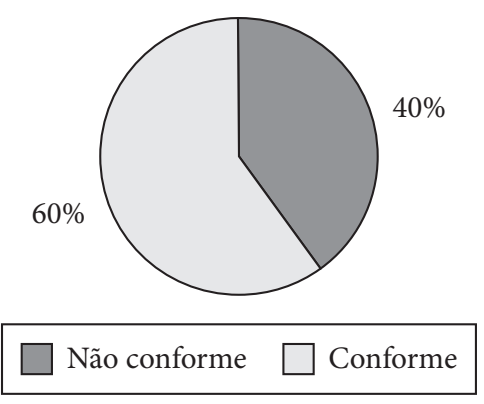

Figura 5. Avaliação dos teores de Umidade quanto à RDC n $360 \mathrm{em}$ amostras de carnes moídas comercializadas em diferentes pontos de venda nas cidades do Rio de Janeiro e Niterói.

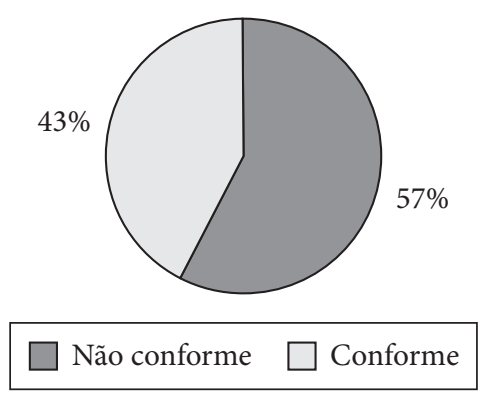

Figura 6. Avaliação dos teores de Umidade quanto à $\mathrm{RDC} \mathrm{n}^{\circ} 360 \mathrm{em}$ amostras de mortadelas, mortadelas tipo Bologna, mortadelas de ave e vendidas a granel em diferentes pontos de venda na cidade do Rio de Janeiro.

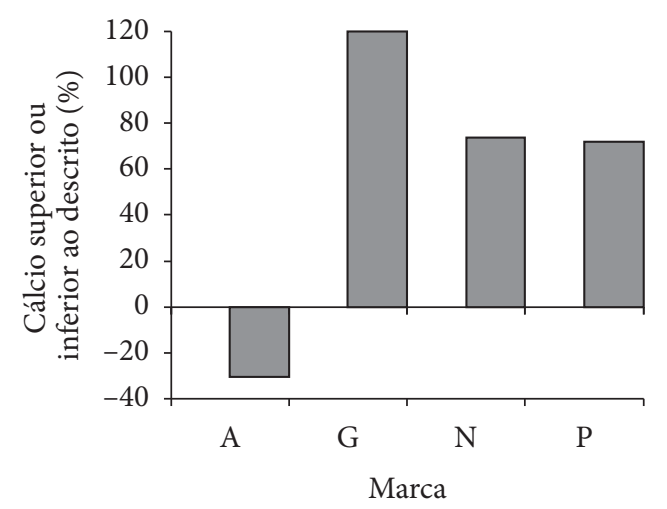

Figura 7. Adequação da quantidade de cálcio encontrada ao descrito na rotulagem em amostras de mortadela e mortadela de ave segundo a RDC n 360 . 
cor foram as mais citadas. Ambas representam fatores decisivos no momento da escolha do produto.

Um dos itens menos citados foram informações nutricionais. As informações nutricionais são de grande importância, já que indicam quais e em que quantidades determinados nutrientes estão presentes naquele produto. Para determinados consumidores, torna-se até perigoso não observar a rotulagem nutricional do produto. Hipertensos e hipercolesterolêmicos, por exemplo, necessitam de uma dieta com baixíssima oferta de sódio e gorduras saturadas, respectivamente. Apenas a leitura do rótulo possibilitará a escolha do melhor alimento a ser consumido em condições de restrição como essas.

Temperatura de conservação é um dos itens mais importantes a ser observado e, de acordo, com a pesquisa percebe-se que esta informação é levada em consideração por uma pequena parte dos entrevistados. Porém, por mais que se tenha o cuidado de observar a temperatura de conservação do produto, nem sempre é possível saber a que temperatura ele está submetido no ponto de venda, já que o balcão pode não ser munido de termômetro ou este estar em local que não seja facilmente visualizado.

Um dado preocupante é que $16 \%$ dos participantes do inquérito não observam qualquer aspecto no produto antes de comprá-lo. As características físicas de um produto denotam o mínimo de qualidade presente ou não. Como já dito, nem toda deterioração é perceptível aos olhos, mas certamente um produto com suas características alteradas, impróprias ou embalagem em estado precário terá suas condições higiênico-sanitárias prejudicadas.

Em relação à temperatura de armazenamento no local de venda, $60 \%$ dos entrevistados afirmaram que costumam observar a temperatura dos balcões de exposição dos produtos refrigerados. Observar a temperatura em que os produtos estão expostos é fundamental para se adquirir um produto refrigerado. Fiscalizar este item é um meio de exigir o cumprimento desta norma pelos estabelecimentos varejistas.

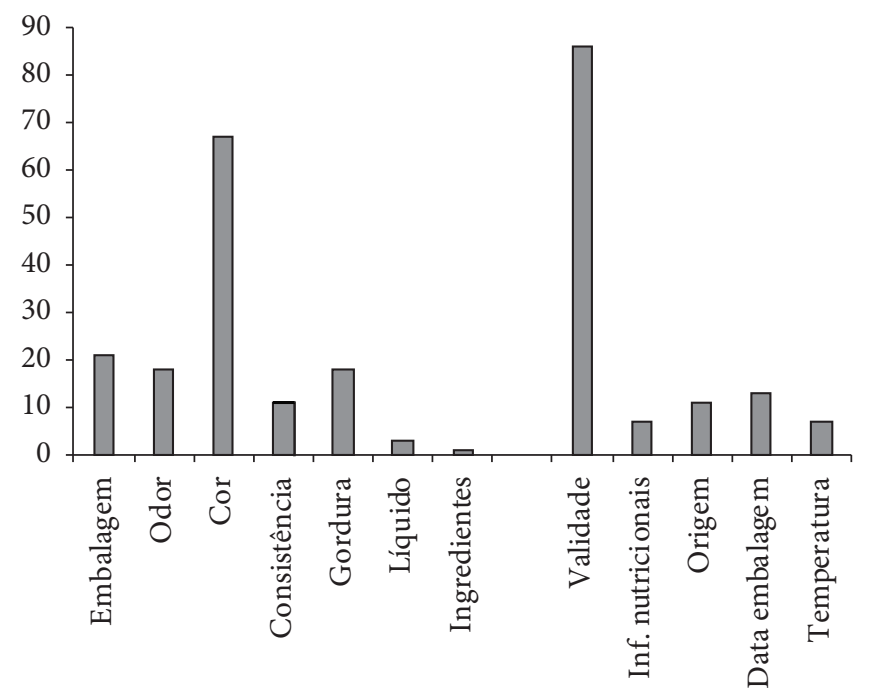

Figura 8. Características e informações observadas pelos consumidores $(\mathrm{n}=84)$ no produto cárneo e na rotulagem.
Culturalmente, a população não detém o hábito de observar informações no rótulo do produto nem a temperatura em que este está sendo conservado. Com o crescimento da tecnologia de alimentos e da área da nutrição, faz-se necessária uma mudança nos hábitos do consumidor a fim de que estes avanços sejam usufruídos de maneira plena. Ambos contribuem para o consumo de alimentos com qualidade tanto higiênico-sanitária quanto nutricional. Há que se criar uma rotina de informação, educação e "fiscalização" por parte do próprio consumidor, proporcionando a garantia do consumo seguro e saudável.

A Figura 9 representa os resultados obtidos quanto ao momento em que os produtos cárneos refrigerados são colocados no carrinho de compras.

Quando questionados sobre o momento em que colocavam produtos cárneos no carrinho de compras, a maior parte dos entrevistados respondeu indo para o caixa. As justificativas para os entrevistados que responderam no início e no meio das compras variaram desde economia de tempo, já que na maioria das vezes o setor do açougue encontra-se cheio, até provocar descongelamento do produto para que no momento da pesagem ele esteja mais leve e, consequentemente, custe menos. Mais uma vez, percebe-se a necessidade de educação do consumidor, já que ao provocar o descongelamento do produto, principalmente em condições inadequadas de temperatura, perdem-se, junto com a água, nutrientes. Produtos refrigerados devem ser os últimos a serem colocados no carrinho para que estes fiquem o menor tempo possível em temperatura ambiente.

Apenas 3\% dos entrevistados se preocupam em manter a temperatura dos produtos refrigerados durante o trajeto entre o ponto de venda e o domicílio, utilizando bolsa térmica. Dependendo da distância entre estes dois pontos e, principalmente em dias mais quentes, é indispensável garantir temperaturas adequadas ao produto para que não haja proliferação de microrganismos e que seu consumo seja seguro. Para Witter (1961), tanto a taxa de crescimento como a atividade bioquímica das bactérias são reduzidas pela diminuição da temperatura e expor produtos refrigerados a temperaturas inadequadas, mesmo que por curtos espaços de tempo, possibilita sua degradação (WITTER, 1961).

A Figura 10 apresenta dados sobre frequência de compra de produtos cárneos e local de armazenamento domiciliar.

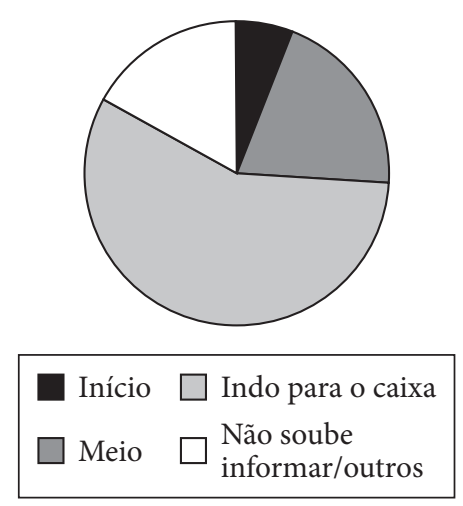

Figura 9. Momento em que produtos cárneos refrigerados são colocados no carrinho de compras. 
Quanto à aquisição de produtos cárneos, a maior parte dos entrevistados afirmou comprá-los semanalmente. Parte dos entrevistados afirmou, ainda, adquiri-los sem frequência específica ou em períodos promocionais.

A forma de armazenamento mais utilizada é o congelamento, seja no congelador ou no freezer. Porém deve-se analisar o custo-benefício desta forma de armazenamento diante da perda nutricional que um produto cárneo pode sofrer.

Um estudo realizado por Andrade et al. (2004) comprovou essa perda nutricional: carnes de ave e boi submetidas à refrigeração e congelamento tiveram queda nos teores de cobre e zinco existentes inicialmente.

A Figura 11 mostra os resultados obtidos quanto aos cuidados tomados pelos consumidores no armazenamento e embalagem de produtos cárneos em domicílio.

Como observado na Figura 11, a maior parte dos entrevistados se preocupa em manter a temperatura dos produtos cárneos e os colocam imediatamente sob refrigeração. Quanto à forma de

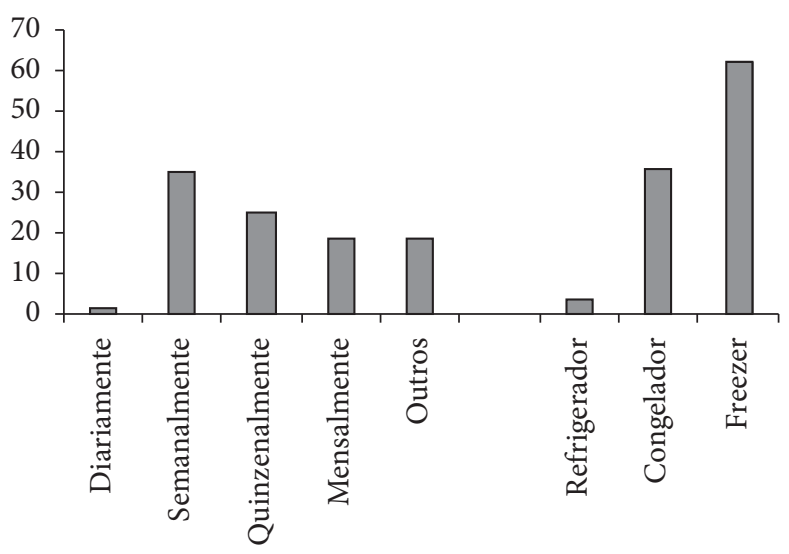

Figura 10. Frequência de compra de produtos cárneos e local de armazenamento no domicílio.

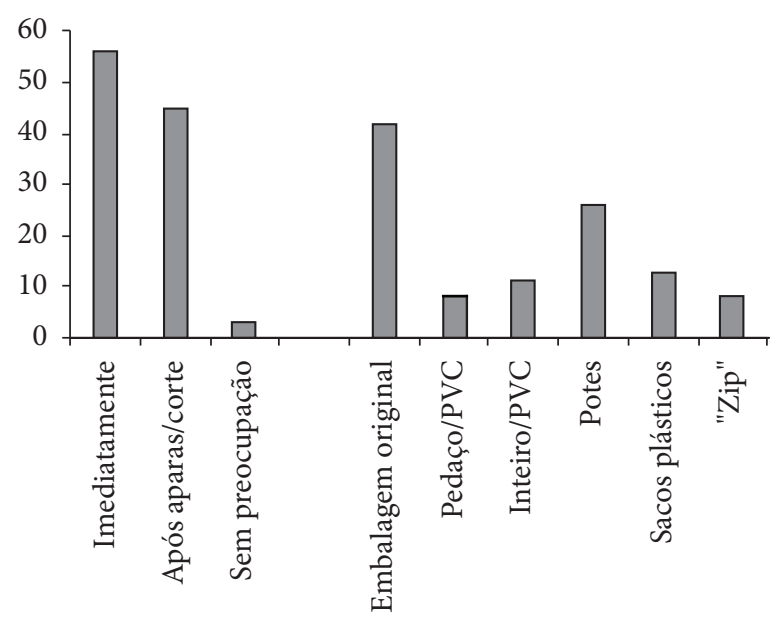

Figura 11. Cuidados no armazenamento e embalagem de produtos cárneos em domicílio. embalagem, a maneira mais citada foi mantendo a embalagem original. Esta não é a melhor forma de armazenar produtos vendidos a granel em supermercados, já que são embalagens extremamente manipuladas e certamente contaminadas, além de estas entrarem em contato com os demais gêneros armazenados no refrigerador ou freezer oferecendo riscos à sua integridade.

\section{Conclusões}

A qualidade físico-química e, consequentemente higiênicosanitária, de produtos cárneos depende de medidas que devem ser obedecidas desde o período pré-abate até o momento do consumo. A distribuição e a comercialização destes produtos merecem especial atenção, já que é nestes processos que se garante a manutenção da qualidade imposta nos processos anteriores e são estas as etapas mais suscetíveis a erros. A fiscalização deve ser mais exigente no que diz respeito ao cumprimento das normas para temperatura, já que grande parte das amostras analisadas encontrava-se armazenada sob temperaturas insatisfatórias. A fiscalização também deve ser mais efetiva quanto aos processos fraudulentos ocorridos tanto na indústria quanto no estabelecimento comercial, pois, além de lesar o consumidor, colocam em risco as condições higiênico-sanitárias dos produtos.

O consumidor deve ter participação ativa na fiscalização exigindo que os postos de venda obedeçam à legislação, a qual garante a qualidade dos produtos comercializados. Porém, educação é fundamental para que este saiba como e o que exigir.

A conscientização da indústria, do estabelecimento comercial e do consumidor é a chave para que sejam comercializados produtos com qualidade tanto nutricional quanto higiênico-sanitária. Trabalhos que eduquem devem ser desenvolvidos para tornar principalmente o consumidor mais informado e participativo do que habitualmente o das gerações passadas tem sido.

\section{Referências bibliográficas}

ANDRADE, E. C. B. et al. Avaliação do teor de cobre e zinco em carnes cruas, processadas termicamente, resfriadas e congeladas no período de um mês. Ciência e Tecnologia de Alimentos, v. 24, n. 3, p. 393-396, 2004.

ANDRADE, E. C. B. Análise de alimentos: uma visão química da nutrição. São Paulo: Ed. VARELA, 2006.

BRASIL. Centro de Vigilância Sanitária de Secretaria da Saúde. Portaria $n^{\circ} 6$ de 10/03/99. Aprova o regulamento técnico que estabelece os parâmetros e critérios para o controle higiênico-sanitário em estabelecimento de alimentos. Brasília, 1999.

BRASIL. Ministério da Agricultura e do Abastecimento. Métodos Analíticos para Controle de Produtos de Origem Animal e seus Ingredientes - LANARA. Brasília, 1989.

BRASIL. Agência Nacional de Vigilância Sanitária - ANVISA. Instituto Adolfo Lutz. Métodos Físico-químicos para análise de alimentos. Brasília, 2005.

BRASIL. Ministério da Agricultura e do Abastecimento. Instrução Normativa $\mathbf{n}^{\circ} \mathbf{8 3}$, de 21 de novembro de 2003. Regulamento Técnico de Identidade e Qualidade de Carnes Moídas. Brasília, 2003.

BRASIL. Ministério da Agricultura e do Abastecimento. Secretaria de Defesa Agropecuária. Instrução Normativa $\mathbf{N}^{\circ} \mathbf{4}$, de 31 de março de 2000. Regulamento Técnico de Identidade e Qualidade de Mortadela. Brasília, 2000. 
BRASIL. Resolução da Diretoria Colegiada - RDC no 360, de 23 de dezembro de 2003. Regulamento Técnico sobre Rotulagem Nutricional de Alimentos Embalados. Brasília, 2003.

FRANCO, B. D. G. M.; LANDGRAF, M. Microbiologia dos alimentos. São Paulo: Ed. Atheneu, 2003.

FREITAS, M. Q. et al. Medidas instrumentais de medida e cor, em mortadela produzida com carne mecanicamente separada de frango. Higiene alimentar, v. 18, n. 126-127, p. 66-70, 2004.

GÓES, J. A. W. et al. Condições de Conservação de Alimentos armazenados por Refrigeração na Cidade de Salvador, Bahia. Higiene Alimentar, v. 18, n. 125 , p. $41-43,2004$.
PIROLA, S. S. Listeria spp. em carne bovina pré moída: isolamento, sorologia, sensibilidade das cepas aos antimicrobianos e relação com a presença de sulfito de sódio. Rio de Janeiro, 2006. 114 p. Dissertação (Mestrado em Higiene Veterinária e Processamento Tecnológico de Produtos de Origem Animal) - Universidade Federal Fluminense, Rio de Janeiro.

THORTON, H. TextBook of Meat Inspection. Londres: Bailliere, Tindall and Cassel, 1968.

WITTER, L. D. Psychrophilic bacteria: a review. Journal of Dairy Science, v. 44, p. 983-1015, 1961. 